\title{
PENERAPAN ANALISIS KORESPONDENSI PADA DATA JUMLAH KUNJUNGAN WISATAWAN MANCANEGARA DI INDONESIA
}

\author{
CITRA KOMANG SARI, MAIYASTRI, IZZATI RAHMI H.G. \\ Program Studi Matematika, \\ Fakultas Matematika dan Ilmu Pengetahuan Alam, Universitas Andalas, \\ Kampus UNAND Limau Manis Padang, Indonesia. \\ email : citrakomangsari@gmail.com
}

\begin{abstract}
Abstrak. Jumlah kunjungan wisatawan yang berkunjung ke suatu negara merupakan salah satu indikator untuk melihat perkembangan pariwisata dari suatu negara. Wisatawan mancanegara yang datang berkunjung ke Indonesia ada yang menggunakan jalur udara, laut maupun darat. Untuk mendeskripsikan hubungan antara asal wisatawan mancanegara dengan pintu masuk yang ada di Indonesia, maka digunakan analisis korespondensi. Dari hasil analisis korespondensi diperoleh bahwa wisatawan mancanegara yang berasal dari negara Singapura lebih banyak berkunjung melalui pintu masuk Batam dan wisatawan yang berasal dari negara Australia lebih banyak berkunjung melalui pintu masuk Ngurah Rai (Bali), sedangkan untuk pintu masuk lainnya tidak memiliki kecendrungan wisatawan dari suatu negara.
\end{abstract}

Kata Kunci: Wisatawan Mancanegara, Analisis Korespondensi

\section{Pendahuluan}

Indonesia merupakan negara yang terkenal dengan berbagai keindahan, baik alam, kebudayaan maupun sejarah bangsa. Banyak tempat-tempat wisata menarik yang dapat dikunjungi wisatawan yang tersebar di seluruh pulau dan provinsi yang ada di Indonesia. Oleh karena itu Indonesia memiliki potensi yang besar di bidang pariwisata. Jika pariwisata dikembangkan dengan baik, maka dapat menghasilkan devisa yang besar bagi negara sehingga dapat meningkatkan perekonomian negara.

Dalam usaha mengembangkan pariwisata internasional sangat diperlukan program yang terarah dan tepat dalam rangka meningkatkan jumlah kedatangan wisatawan mancanegara [1]. Perkembangan pariwisata suatu negara selalu dikaitkan dengan jumlah wisatawan yang berkunjung ke negara tersebut. Jumlah wisatawan yang berkunjung ke suatu negara merupakan salah satu indikator untuk melihat perkembangan pariwisata dari suatu negara.

Wisatawan mancanegara yang datang berkunjung ke Indonesia ada yang menggunakan jalur udara seperti Bandara Soekarno-Hatta (Banten) dan Bandara Ngurah Rai (Bali). Ada juga yang menggunakan jalur laut seperti Pelabuhan Laut Kota Batam dan Kota Tanjung Pinang. Untuk melihat hubungan antara pintu masuk dengan asal negara wisatawan dan juga untuk melihat kecendrungan wisatawan dalam memilih pintu masuk, serta untuk melihat wisatawan dari negara mana saja 
yang memiliki kesamaan dalam memilih pintu masuk. maka digunakan salah satu analisis peubah ganda yaitu Analisis Korespondensi. Analisis korespondensi merupakan teknik multivariat yang mengeksplorasi data dari sebuah tabel kontingensi untuk melihat hubungan antara dua variabel kategorik.

\section{Landasan Teori}

Analisis Korespondensi adalah suatu ilmu yang mempelajari hubungan antara dua atau lebih variabel kategori. Dalam analisis korespondensi variabel yang digunakan adalah variabel kategori (nominal/ordinal) yang mempunyai banyak kategori dan tidak mempunyai suatu metode khusus untuk menentukan atau memutuskan jumlah dimensi yang tepat.

Matriks korespondensi dinyatakan sebagai berikut

$$
P_{a \times b}=\left(p_{i j}\right)=\left(\frac{n_{i j}}{n}\right)
$$

dengan

$$
\begin{aligned}
n_{i j} & : \text { frekuensi pengamatan dari baris ke- } i \text { dan kolom ke- } j \\
n & =\sum_{i=1}^{a} \sum_{j=1}^{b} n_{i j}
\end{aligned}
$$

Jadi, matriks korespondensi $(P)$ merupakan matriks yang elemen-elemennya merupakan elemen-elemen dari tabel kontingensi yang dibagi dengan seluruh jumlah $n$. Matriks Korespondensi $(P)$ yang berukuran $a \times b$ dengan $p_{i j} \geq 0$, menyatakan frekuensi dari $\operatorname{sel}(i, j)$ yang mana dapat dinyatakan dalam bentuk matriks sebagai berikut

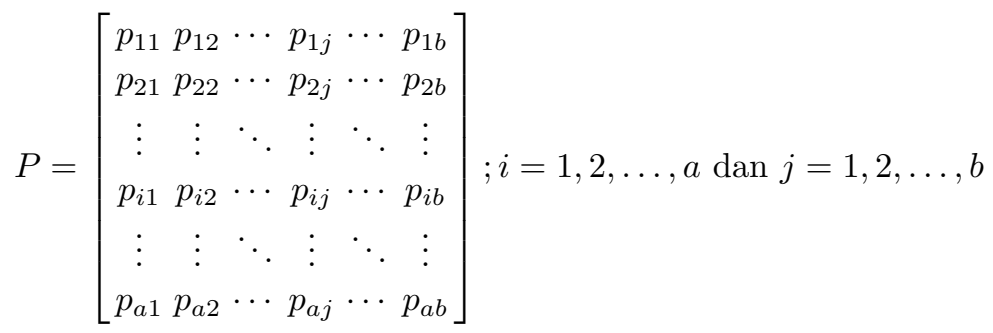

Apabila setiap elemen pada suatu baris dijumlahkan, maka diperoleh vektor jumlah baris dari matriks $P$ yaitu $r$ dengan rumusan sebagai berikut

$$
r_{i}=\sum_{j=1}^{b} p_{i j} \text { atau } r_{(a \times 1)}=P_{(a \times b)} 1_{(b \times 1)}
$$

Dengan kata lain $r=P 1=\left(p_{1} \cdot p_{2} . \ldots p_{a} \cdot\right)^{T}$, dimana $1=\left(\begin{array}{llll}1 & 1 & \cdots & 1\end{array}\right)^{T}$. Sehingga bentuk matriks diagonal $D_{r}=\operatorname{diag}(r)$ yang berukuran $a \times a$ yang unsur-unsur diagonalnya adalah unsur-unsur vektor jumlah baris $r$ yaitu

$$
D_{r}=\left[\begin{array}{cccc}
p_{1} & 0 & \cdots & 0 \\
0 & p_{2} & \cdots & 0 \\
\vdots & \vdots & \ddots & \vdots \\
0 & 0 & \cdots & p_{a} .
\end{array}\right]
$$


Apabila setiap elemen pada suatu kolom dijumlahkan, maka diperoleh vektor jumlah kolom dari matriks $P$ yaitu $c$ dengan rumusan sebagai berikut

$$
c_{j}=\sum_{i=1}^{a} p_{i j} \text { atau } c_{(b \times 1)}=P_{(b \times a)}^{T} 1_{(a \times 1)}
$$

Dengan kata lain $c=P^{T} 1=\left(\begin{array}{llll}p_{\cdot 1} & p_{\cdot 2} & \ldots & p_{\cdot b}\end{array}\right)^{T}$, dimana $1=\left(\begin{array}{llll}1 & 1 & \cdots & 1\end{array}\right)^{T}$. Sehingga bentuk matriks diagonal $D_{c}=\operatorname{diag}(c)$ yang berukuran $b \times b$ yang unsur-unsur diagonalnya adalah unsur-unsur vektor jumlah kolom $c$ yaitu

$$
D_{c}=\operatorname{diag}(c)=\left[\begin{array}{cccc}
p_{\cdot 1} & 0 & \cdots & 0 \\
0 & p_{\cdot 2} & \cdots & 0 \\
\vdots & \vdots & \ddots & \vdots \\
0 & 0 & \cdots & p_{\cdot b}
\end{array}\right]
$$

\subsection{Profil Baris dan Profil Kolom}

Profil adalah proporsi dari setiap baris atau kolom matriks korespondensi yaitu setiap frekuensi pengamatan baris ke- $i$ dan kolom ke- $j$ dibagi dengan jumlah setiap total baris dan kolomnya masing-masing. Karena matriks diagonal kolom dan baris masing-masing berukuran $b \times b$ dan $a \times a$, maka dapat dibentuk matriks $R$ yang berukuran $a \times b$ sebagai berikut

$$
R=D_{r}^{-1} P=\left[\begin{array}{cccc}
\frac{p_{11}}{p_{1}} & \frac{p_{12}}{p_{1}} & \cdots & \frac{p_{1 b}}{p_{1}} \\
\frac{p_{21}}{p_{2}} & \frac{p_{22}}{p_{2}} & \cdots & \frac{p_{2 b}}{p_{2}} \\
\vdots & \vdots & \ddots & \vdots \\
\frac{p_{a 1}}{p_{a}} & \frac{p_{a 2}}{p_{a} .} & \cdots & \frac{p_{a b}}{p_{a} .}
\end{array}\right]
$$

Matriks $R$ disebut profil baris (row profile) dalam ruang berdimensi $b$ dengan jumlah unsur-unsur profil dari baris sama dengan satu. Sedangkan matriks $C$ berukuran $b \times a$ adalah

$$
C=D_{c}^{-1} P^{T}=\left[\begin{array}{cccc}
\frac{p_{11}}{p_{\cdot 1}} & \frac{p_{21}}{p_{\cdot 1}} & \cdots & \frac{p_{a 1}}{p \cdot 1} \\
\frac{p_{12}}{p_{\cdot 2}} & \frac{p_{22}}{p_{\cdot 2}} & \cdots & \frac{p_{a 2}}{p \cdot 2} \\
\vdots & \vdots & \ddots & \vdots \\
\frac{p_{1 b}}{p \cdot b} & \frac{p_{2 b}}{p \cdot b} & \cdots & \frac{p_{a b}}{p \cdot b}
\end{array}\right]
$$

Matriks $C$ disebut sebagai profil kolom (column profile) dalam ruang berdimensi $a$, dimana jumlah unsur-unsur dari profil kolom sama dengan satu. Untuk menampilkan profil-profil baris dan profil-profil kolom ke dalam ruang euclid yang berdimensi dua digunakan pendekatan jarak khi-kuadrat, yaitu

$$
\chi^{2}=\sum_{i=1}^{a} \sum_{j=1}^{b} \frac{\left(n_{i j}-\frac{n_{i \cdot n \cdot j}}{n}\right)^{2}}{\frac{n_{i \cdot n \cdot j}}{n}}=n \sum_{i=1}^{a} \sum_{j=1}^{b} \frac{\left(p_{i j}-p_{i \cdot p \cdot j}\right)^{2}}{p_{i \cdot p_{\cdot j}}}
$$

Misalkan $E=D_{r}^{-1}\left(P-r c^{T}\right) D_{c}^{-1}\left(P-r c^{T}\right)^{T}$ dengan $D_{r}$ adalah matriks diagonal baris, $D_{c}$ adalah matriks diagonal kolom dari suatu matriks korespondensi $(P), r$ 
merupakan vektor jumlah baris, dan $c$ merupakan vektor jumlah kolom. Maka

$$
\chi^{2}=n \operatorname{tr}(E)=n \sum_{i=1}^{m} \lambda_{i}^{2}
$$

dengan $\lambda_{1}^{2} \geq \lambda_{2}^{2} \geq \ldots \geq \lambda_{m}^{2}$ adalah nilai eigen atau akar ciri tak nol dari $E$ dan $m=\operatorname{rank}(E)=\operatorname{rank}\left(P-r c^{T}\right)=(\min (a, b)-1) \cdot \chi^{2}$ juga dapat ditulis sebagai berikut

$$
\chi^{2}=n \sum_{i=1}^{a} p_{i} d_{i}^{2} ; \quad d_{i}^{2}=\left(r_{i}-c\right)^{T}\left(r_{i}-c\right)
$$

\subsection{Peguraian Nilai Singular}

Untuk mereduksi dimensi data berdasarkan keragaman data (nilai eigen/nilai inersia) terbesar dengan mempertahankan informasi optimum, maka diperlukan penguraian nilai singular. Matriks yang akan diuraikan dalam analisis korespondensi adalah matriks $D_{r}^{-1 / 2}\left(P-r c^{T}\right) D_{c}^{-1 / 2}$ yang akan menghasilkan matriks $U$ berukuran $n \times r$ dan matriks $A$ berukuran $p \times r$, dan $L$ merupakan suatu matriks diagonal yang elemen-elemen utamanya adalah nilai singular, dimana nilai singular adalah akar dari nilai eigen.

\subsection{Penguraian Nilai Singular Umum}

Untuk menentukan anak ruang euclid dan memproyeksikan semua profil baris kedalam anak ruang Euclid digunakan penguraian nilai singular umum atau generalized singular value decomposition (GSVD). Koordinat dari baris dan kolom ditentukan dengan menggunakan GSVD dari matriks $\left(P-r c^{T}\right)$, yaitu $A \Lambda B^{T}, \Lambda$ merupakan matriks diagonal yang unsur-unsur diagonalnya merupakan nilai singular dari matriks $\left(P-r c^{T}\right)$, dimana berlaku $A^{T} D_{r}^{-1} A=I_{m}$ dan $B^{T} D_{c}^{-1} B=I_{m}$.

Tabel 1. Koordinat Baris dan Koordinat Kolom

\begin{tabular}{|c|c|c|}
\hline & Rumus Koordinat Baris & Rumus Koordinat Kolom \\
\hline Analisis Profil Baris & $F=D^{-1} A$ & $G=D_{c}^{-1} B$ \\
\hline Analisis Profil Kolom & $F=D_{r}^{-1} A$ & $G=D_{c}^{-1} B$ \\
\hline Analisis Baris dan Kolom & $F=D^{-1} A$ & $G=D_{c}^{-1} B$ \\
\hline
\end{tabular}

\subsection{Nilai Eigen}

Misal dipresentasikan profil-profil baris dan profil-profil kolom ke dalam ruang berdimensi $d \leq m$. Koordinat dari $a$ baris dari matriks yang dibentuk dengan mengambil $d$ kolom pertama dari $F=D_{r}^{-1} A \Lambda$ dan koordinat dari $b$ profil kolom adalah $b$ buah baris dari matriks yang dibentuk dengan mengambil $d$ kolom pertama dari $G=D_{c}^{-1} B \Lambda$. Karena total nilai eigen merepresentasikan semua informasi 
dalam seluruh ruang adalah $\operatorname{tr}(E)=n \sum_{i=1}^{m} \lambda_{i}^{2}$, maka pendekatan ruang berdimensi $m$ dengan ruang berdimensi $d$ dikatakan baik jika $\sum_{i=1}^{d} \lambda_{i}$ mendekati total nilai eigen atau $\sum_{i=k+1}^{m} \lambda_{i}^{2}$ mendekati nol. Sehingga besaran relatif untuk mengukur besarnya kehilangan informasi dapat dirumuskan sebagai berikut

$$
L=1-\frac{\sum_{i=1}^{d} \lambda_{i}^{2}}{\sum_{i=1}^{m} \lambda_{i}^{2}}
$$

\section{Data dan Metode Penelitian}

Data yang digunakan pada penelitian ini merupakan data sekunder yang diperoleh dari website kementrian pariwisata Indonesia yaitu http://www.parekraf.go.id yang diolah menggunakan analisis korespondensi.

\section{Pembahasan}

Dikarenakan data yang digunakan merupakan data sekunder sehingga tidak ada asumsi-asumsi yang mendukung untuk data, maka pada proses analisis datanya, data negara lain dikeluarkan agar tidak mempengaruhi hasil analisis, selanjutnya negara Bahrain digabungkan dengan Arab Saudi agar uji khi-kuadrat bisa digunakan. Sebelum masuk ke proses awal analisis korespondensi, dilakukan uji kebebasan untuk melihat ada tidaknya hubungan antara asal wisatawan yang berkunjung ke Indonesia dan pintu masuk utama yang ada di Indonesia. Tabel 2 memperlihatkan hasil uji khi-kuadrat untuk melihat hubungan antara asal wisatawan dan pintu masuknya.

Tabel 2. Hasil Uji Khi-Kuadrat terhadap Jumlah Wisatawan Mancanegara yang berkunjung ke Indonesia berdasarkan Kebangsaan dan Pintu Masuknya

\begin{tabular}{|c|c|c|c|}
\hline \multicolumn{4}{|c|}{ Chi-Square Tests } \\
\hline & Value & Df & P Value \\
\hline Pearson Chi-Square & 5800349.07 & 342 & 0.000 \\
\hline
\end{tabular}

Berdasarkan Tabel 2 dapat dilihat bahwa $p$ value yang didapatkan adalah 0,000 (lebih kecil dari $\alpha=0.05$ ). Ini berarti bahwa terdapat hubungan antara asal wisatawan mancanegara yang berkunjung ke Indonesia dengan pintu masuk untuk berkunjung ke Indonesia. Hal ini juga berarti bahwa terdapat kecendrungan wisatawan mancanegara dari negara tertentu untuk memilih pintu masuk. Untuk mengetahui hal tersebut, maka dilakukan analisis korepondensi.

$$
C=\sqrt{\frac{\chi^{2}}{N+\chi^{2}}}=\sqrt{\frac{5800349,07}{7694184+5800349,07}}=\sqrt{0,42982955}=0,65561387 .
$$

Koefisien kontingensi yang diperoleh cukup tinggi Hal ini berarti bahwa tingkat keeratan hubungan antara asal wisatawan mancanegara dengan pintu masuknya cukup kuat yang ditandai dengan nilai koefisien kontingensi yg lebih besar dari 0,5. 
Berdasarkan Profil Baris yang diperoleh, jika diperhatikan profil setiap kolom, maka dapat dilihat bahwa nilai terbesar untuk setiap kolom menunjukkan asal wisatawan mancanegara yang paling banyak berkunjung ke Indonesia untuk masingmasing pintu masuk utama.

Tabel 3. Asal Wisatawan Mancanegara yang paling banyak berkunjung ke Indonesia melalui Pintu Masuk Utama

\begin{tabular}{|c|c|}
\hline Pintu Masuk Utama & Wisatawan yang paling banyak berkunjung \\
\hline 1. Soekarmo-Hatta (Banten) & Arab Saudi (R) \\
\hline 2. Ngurah Rai (Bali) & Australia (K) \\
\hline 3. Kualanamu $I A$ (Medan) & Malaysia (B) \\
\hline 4. Batam (Kep. Riau) & Singapura (A) \\
\hline 5. Juanda (Jawa Timur) & Hongkong (I) \\
\hline 6. Sam Ratulangi (Sulawesi Utara) & Jerman (O) \\
\hline 7. Entikong (Kalimantan Barat) & Malaysia (B) \\
\hline 8. BIM (Sumatera Barat) & Malaysia (B) \\
\hline 9. Adi Sumamo (Jawa Tengah) & Prancis $(\mathrm{P})$ \\
\hline 10. Makasar (Sulawesi Selatan) & Malaysia (B) \\
\hline 11. BIL (Nusa Tenggara Barat) & Inggris (M) \\
\hline 12. Sepinggan (Kalimantan Timur) & Mesir (S) \\
\hline 13. Sultan Syarif K II (Riau) & Malaysia (B) \\
\hline 14. Tj. Priok (Jakarta) & Amerika Serikat (L) \\
\hline 15. Tj. Pinang (Kep. Riau) & Singapura (A) \\
\hline 16. Adi Sucipto (DIY) & Malaysia (B) \\
\hline 17. Husein Sastranegara (Jawa Barat) & Malaysia (B) \\
\hline 18. Tj. Uban (Kep. Riau) & Philipina (H) \& Hongkong (I) \\
\hline 19. Tj. Balai Karimun (Kep. Riau) & Malaysia (B) \\
\hline
\end{tabular}

Berdasarkan profil kolom yang diperoleh, jika diperhatikan profil setiap baris, maka dapat dilihat bahwa nilai terbesar untuk setiap baris menunjukkan pintu masuk utama yang paling banyak dikunjungi oleh masing-masing negara.

Dari hasil analisis korespondensi yang dilakukan, diperoleh juga informasi mengenai akar ciri (nilai eigen) yang menjelaskan besarnya keragaman yang dapat dijelaskan oleh profil baris dan profil kolom. Hal ini dapat dilihat pada Tabel 5 .

Berdasarkan Tabel 5 dapat dilihat bahwa persentase proporsi kumulatif dua nilai eigen pertama dari data jumlah kunjungan wisatawan mancanegara berdasarkan kebangsaan dan pintu masuknya adalah sebesar 96,4\%. Ini berarti bahwa peta dua dimensi sudah mewakili 96,4\% informasi dari data asal yang awalnya dalam ruang berdimensi 19 dan hilangnya informasi dari data hanya sebesar 3,6\% . Selanjutnya akan digambarkan plot korespondensi dalam peta dua dimensi dikarenakan peta dua dimensi sudah mewakili 96,4\% informasi data.

Gambar 1 menggambarkan plot korespondensi dari data jumlah kunjungan wisatawan mancanegara di Indonesia berdasarkan kebangsaan dan pintu masuknya. Dari Gambar 1 dapat dilihat bahwa

(i) Wisatawan yang berasal dari negara A (Singapura) lebih banyak berkunjung ke Indonesia melalui pintu masuk 4 (Batam) dan pintu masuk Batam kebanyakan dimasuki oleh wisatawan yang berasal dari negara Singapura.

(ii) Wisatawan yang berasal dari negara K (Australia) lebih banyak berkunjung 
Tabel 4. Pintu Masuk Utama yang paling banyak dikunjungi oleh wisatawan

\begin{tabular}{|l|l|}
\hline \multicolumn{1}{|c|}{ Asal Wisatawan } & \multicolumn{1}{c|}{ Pintu masuk yang paling banyak dikunjungi } \\
\hline A. Singapura & Tanjung Pinang, Kep. Riau (15) \\
B. Malaysia & BIM, Sumatera Barat (8) \\
C. Jepang & Soekamo-Hatta, Banten (1) \\
D. Korea Selatan & Ti. Uban, Kep. Riau (18) \\
E. Taiwan & Juanda, Jawa Timur (5) \\
F. China & Ngurah Rai, Bali (2) \\
G. India & Sepinggan, Kalimantan Timur (12) \\
H. Philipina & Tj. Uban, Kep. Riau (18) \\
I. Hongkong & Sam Ratulangi, Sulawesi Utara (6) \\
J. Thailand & Juanda, Jawa Timur (5) \\
K. Australia & Ngurah Rai, Bali (2) \\
L. Amerika Serikat & Ti. Priok, Jakarta (14) \\
M. Inggris & Tj. Priok, Jakarta (14) \\
N. Belanda & Ti. Priok, Jakarta (14) \\
O. Jerman & Sam Ratulangi, Sulawesi Utara (6) \\
P. Prancis & Adi Sumamo, Jawa Tengah (9) \\
Q. Rusia & Ngurah Rai, Bali (2) \& Ti. Priok, Jakarta (14) \\
R. Arab Saudi & Soekarmo-Hatta, Banten (1) \\
S. Mesir & Sepinggan, Kalimantan Timur (12) \\
T. Uni Emirat Arab & Soekamo-Hatta, Banten (1) \\
\hline
\end{tabular}

Tabel 5. Nilai Eigen Jumlah Kunjungan Wisatawan berdasarkan Pintu Masuk Utama dan Kebangsaaannya

\begin{tabular}{|c|c|c|c|c|}
\hline \multicolumn{5}{|c|}{ Summary } \\
\hline \multirow{2}{*}{ Dimension } & \multirow{2}{*}{$\begin{array}{c}\text { Singular } \\
\text { Value }\end{array}$} & $\begin{array}{c}\text { Eigen } \\
\text { value }\end{array}$ & Accounted for & Cumulative \\
\cline { 4 - 5 } & & & & \\
\hline 1 & 2.426 & 5.885 & 0.791 & 0.791 \\
\hline 2 & 1.131 & 1.280 & 0.172 & 0.964 \\
\hline 3 & 0.510 & 0.260 & 0.035 & 0.998 \\
\hline 4 & 0.101 & 0.010 & 0.001 & 1.000 \\
\hline 5 & 0.022 & 0.000 & 0.000 & 1.000 \\
\hline 6 & 0.018 & 0.000 & 0.000 & 1.000 \\
\hline 7 & 0.014 & 0.000 & 0.000 & 1.000 \\
\hline 8 & 0.009 & 0.000 & 0.000 & 1.000 \\
\hline 9 & 0.008 & 0.000 & 0.000 & 1.000 \\
\hline 10 & 0.004 & 0.000 & 0.000 & 1.000 \\
\hline 11 & 0.003 & 0.000 & 0.000 & 1.000 \\
\hline 12 & 0.002 & 0.000 & 0.000 & 1.000 \\
\hline 13 & 0.002 & 0.000 & 0.000 & 1.000 \\
\hline 14 & 0.001 & 0.000 & 0.000 & 1.000 \\
\hline 15 & 0.001 & 0.000 & 0.000 & 1.000 \\
\hline 16 & 0.000 & 0.000 & 0.000 & 1.000 \\
\hline 17 & 0.000 & 0.000 & 0.000 & 1.000 \\
\hline 18 & 0.000 & 0.000 & 0.000 & 1.000 \\
\hline Total & & 7.436 & 1.000 & 1.000 \\
\hline
\end{tabular}

ke Indonesia melalui pintu masuk 2 yaitu Ngurah Rai (Bali) dan pintu masuk Ngurah Rai (Bali) kebanyakan dimasuki oleh wisatawan yang berasal dari negara Australia.

(iii) Wisatawan yang berasal dari negara B (Malaysia) lebih banyak berkunjung melalui pintu masuk pertama yaitu Soekarno-Hatta (Banten). Pintu masuk Soekarno-Hatta (Banten) tidak memiliki kecendrungan wisatawan yang berasal dari satu negara saja, hal ini dapat dilihat dari posisi titik pintu masuk pertama yaitu Soekarno-Hatta (Banten) yang dekat dengan 
beberapa negara.

(iv) Wisatawan yang berasal dari negara Jepang, Korea Selatan, Hongkong, Taiwan, China, India, Philipina, Thailand, Amerika, Inggris, Belanda, Jerman, Prancis, Rusia, Arab Saudi, Uni Emirat Arab, Bahrain, dan Mesir tidak memiliki kecendrungan untuk masuk ke Indonesia melalui suatu pintu masuk tertentu. Wisatawan tersebut masuk melalui pintu Kualanamu International Airport (Medan), BIM (Sumatera Barat), Entikong (Kalimantan Barat), Sepinggan (Kalimantan Timur), Juanda (Jawa Timur), Adi Sumarno (Jawa Tengah), Tj. Priok (Jakarta), Adi Sucipto (DIY), BIL (Nusa Tenggara Barat), Hussein Sastranegara (Jawa Barat), Tj. Pinang (Kep. Riau), Tj. Balai Karimun (Kep. Riau), Tj. Uban (Kep. Riau), Sultan Syarif K II (Riau), Sam Ratulangi (Sulawesi Utara), Makasar (Sulawesi Selatan), Soekarno-Hatta (Banten), Ngurah Rai (Bali), dan Batam.

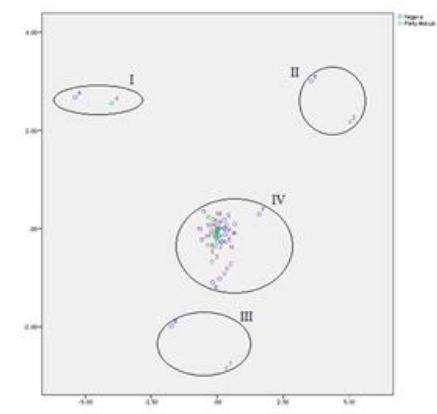

Gambar 1. Plot Korespondensi Data Kunjungan Wisatawan Mancanegara

\section{Kesimpulan}

Berdasarkan hasil analisis korespondensi dalam penelitian ini, maka dapat disimpulkan bahwa wisatawan yang berasal dari negara Singapura lebih banyak berkunjung ke Indonesia melalui pintu masuk Batam dan wisatawan yang berasal dari negara Australia lebih banyak berkunjung ke Indonesia melalui pintu masuk Ngurah Rai (Bali) serta wisatawan yang berasal dari negara Malaysia lebih banyak berkunjung melalui pintu masuk Soekarno-Hatta (Banten). Sedangkan untuk wisatawan mancanegara lainnya tidak ada kecendrungan masuk melalui pintu masuk tertentu. Pintu masuk Batam kebanyakan dimasuki oleh wisatawan yang berasal dari singapura dan untuk pintu masuk Ngurah Rai (Bali) lebih banyak dimasuki oleh wisatawan yang berasal dari negara Australia. Sedangkan pintu masuk lainnya tidak memiliki kecendrungan wisatawan dari suatu negara.

\section{Daftar Pustaka}

[1] BPS. 2015. Statistik Kunjungan Wisatawan Mancanegara 2014. Jakarta: BPS. 
64 Citra Komang Sari dkk.

[2] Cullen, C. G. 1992. Aljabar Linier dengan Penerapannya. Jakarta: Gramedia Pustaka Utama.

[3] H, Anton. 1987. Aljabar Linier Elementer. Jakarta: Erlangga.

[4] Howard, Anton dan Rorres, Chris. 2004. Aljabar Linier Elementer. Jakarta: Erlangga.

[5] Johnson, R. A, dan Wichern, D. W. 2007. Applied Multivariate Statistical Analysis. New Jersey: Prentice-Hall Inc.

[6] Jollifie,I. T. 1986. Principal Components Analysis. New York: Springer-Verlag New York Inc.

[7] Kadir. 2015. Statistika Terapan: Konsep, Contoh, dan Analisa Data dengan Program SPSS/Lisrel dalam Penelitian. Jakarta: PT Rajagrafindo Persada.

[8] Lipschuts, Seymour, dan Lipson, M. L. 2006. Schaum's Outlines Teori dan Soal Aljabar Linier. Jakarta: Erlangga.

[9] Matjik, A. A dan Sumertajaya, I. M. 2011. Sidik Peubah Ganda. Bogor: IPB Press.

[10] Pitana, I. G dan Diarta, I. K. S. 2009. Pengantar Ilmu Pariwisata. Yogyakarta: Andi Offset.

[11] Siegel, Sidney. 1992. Statistik Nonparametik. Jakarta: PT Gramedia Pustaka Utama.

[12] Spiegel, M. R dan Stephens, L. J. 2007. Schaum's Outlines Teori dan Soal-Soal Statistik. Jakarta: Erlangga.

[13] Walpole, R. E. 1988. Pengantar Statistika. Jakarta: PT Gramedia Pustaka Utama. 